\title{
Targeted metabolomics for serum amino acids and acylcarnitines in patients with lung cancer
}

\author{
JUNJUN NI $^{1,2}$, LI XU ${ }^{2}$, WEI LI ${ }^{2}$, CHUNMEI ZHENG ${ }^{2}$ and LIJUN WU ${ }^{1}$ \\ ${ }^{1}$ Department of Medicinal Chemistry and Natural Medicine Chemistry, College of Pharmacy, Harbin Medical University, \\ Harbin, Heilongjiang 150081; ${ }^{2}$ Beijing Harmony Health Medical Diagnostics Co., Ltd., Beijing 101111, P.R. China
}

Received April 22, 2018; Accepted December 6, 2018

DOI: $10.3892 /$ etm.2019.7533

\begin{abstract}
Lung cancer is one of the most prevalent types of cancer, but accurate diagnosis remains a challenge. The aim of the present study was to create a model using amino acids and acylcarnitines for lung cancer screening. Serum samples were obtained from two groups of patients with lung cancer recruited in 2015 (including 40 patients and 100 matched controls) and 2017 (including 17 patients and 30 matched controls). Using a metabolomics method, 21 metabolites (13 types of amino acids and 8 types of acylcarnitines) were measured using liquid chromatography-tandem mass spectrometry. Data (from the 2015 and 2017 data sets) were analysed using a Mann-Whitney U test, Student's t-test, Welch's F test, receiver-operator characteristic curve or logistic regression in order to investigate the potential biomarkers. Six metabolites (glycine, valine, methionine, citrulline, arginine and C16-carnitine) were indicated to be involved in distinguishing patients with lung cancer from healthy controls. The six discriminating metabolites from the 2017 data set were further analysed using Partial least squares-discriminant analysis (PLS-DA). The PLS-DA model was verified using Spearman's correlation analysis and receiver operating characteristic curve analysis. These results demonstrated that the PLS-DA model using the six metabolites (glycine, valine, methionine, citrulline, arginine and C16-carnitine) had a strong ability to identify lung cancer. Therefore, the PLS-DA model using glycine, valine, methionine, citrulline, arginine and C16-carnitine may become a novel screening tool in patients with lung cancer.
\end{abstract}

Correspondence to: Professor Lijun Wu, Department of Medicinal Chemistry and Natural Medicine Chemistry, College of Pharmacy, Harbin Medical University, 157 Baojian Road, Nangang, Harbin, Heilongjiang 150081, P.R. China

E-mail:wulijunmedicine@163.com

Key words: lung cancer, liquid chromatography-tandem mass spectrometry, amino acids, acylcarnitines, metabolomics

\section{Introduction}

Lung cancer is one of the most prevalent types of cancer, with a mean 5 -year survival rate of $<15 \%$ (1). This is mainly due to the lack of diagnostic technology able to detect the disease during its early stages. The 5-year survival rate may increase up to $60 \%$ when lung cancer is detected prior to metastasizing to lymph nodes or distant sites (1). Therefore, there is an urgent need to identify biomarkers for early diagnosis. The development of metabolomics, genomics and proteomics has produced promising novel methods for the early detection of cancer $(2,3)$. Metabolomics may measure low molecular weight metabolites $(<1,000 \mathrm{amu})$, including amino acids, lipids, fatty acids and carbohydrates, which are the end products of biochemical pathways involved in cellular physiology, structure and signal transduction (4). As alterations in the levels of these metabolites may indicate an abnormal status of the cells (5), metabolomics may be a useful approach to screening patients with different diseases $(6,7)$.

Of all metabolites, amino acids and acylcarnitines are potential biomarkers for diagnosing cancer as they serve an essential role in cell physiology as basic metabolites and metabolic regulators. Amino acid profiles in association with lung cancer have been studied previously (8-16). However, inconsistent results were reported. Maeda et al (11) demonstrated that the levels of 8 amino acids (alanine, tyrosine, proline, glycine, isoleucine, phenylalanine, ornithine and lysine) were increased, whereas histidine was decreased in the plasma of patients with non-small cell lung cancer, compared with age-, sex- and smoking status-matched controls using liquid chromatography-mass spectrometry (LC-MS). Rocha et al (12) reported that the plasma levels of amino acids (including alanine, glutamine, valine, tyrosine and histidine) in patients with cancer were lower compared with the healthy controls. Wen et al (14), using a combination of gas chromatography-mass spectrometry and LC-MS, revealed that the levels of five amino acids (alanine, glutamine, glycine, threonine and 5-hydroxytryptophan) were significantly decreased in the plasma of patients with stage I human lung adenocarcinoma compared with the healthy controls. Therefore, no consistency was obtained on the association of amino acids with lung cancer. The inconsistency may be due to various factors, including the differences in Tumor-Node-Metastasis (TNM) stages, pathological types and genotypes. In a previous study, a liquid 
chromatography-tandem mass spectrometry (LC-MS/MS) method was developed in order to measure 13 types of amino acids and 8 types of acylcarnitines in the serum of patients with lung cancer with ideal accuracy and precision (17). This method was successfully used in 40 patients with lung cancer and healthy controls, and the results revealed that a number of metabolites were significantly different between the patients with lung cancer and the healthy controls (17). In the present study, a group of patients with lung cancer with detailed clinical characteristics were recruited, and screening for potential biomarkers for lung cancer from two data sets was attempted. Two data sets from different time periods were used to ensure reliability of the results. Hence, the aim of the present study was to build a model using amino acids and acylcarnitines for lung cancer screening.

\section{Materials and methods}

Ethical approval. The Regional Committee for Medical and Health Research Ethics approved the study protocol, and all patients provided written informed consent for participation in the study. All procedures performed in the present study involving human participants were in accordance with 1964 Helsinki declaration and its later amendments, or comparable ethical standards.

Subjects. Two data sets were obtained in the present study. The data sets were recruited between January and October 2015, and between May and September 2017 at the Department of Thoracic Surgery of Guang'anmen Hospital (Beijing, China) and the Department of Thoracic Surgery of China-Japan Friendship Hospital (Beijing, China), respectively. Patients diagnosed with lung cancer were prospectively recruited, and the control group included subjects with no evidence of lung cancer. The inclusion criteria for patients with lung cancer were as follows: Participants pathologically confirmed to have malignant tumor types were consecutively recruited from the two sites at their regular appointments. The exclusion criteria for the patients with lung cancer were as follows: Diagnosis of diseases other than lung disease, other cancer types and a history of any thoracic surgery within 30 days prior to enrolment. In the two data sets, participants in the control groups matched the patient groups in terms of age and sex. The inclusion criteria for control groups were as follows: Participants without discomfort in the respiratory system, and diagnosed with no abnormality under X-ray analysis. The exclusion criteria for control groups were as follows: A diagnosis of any cancer type and a history of any thoracic surgery within 30 days prior to enrolment. The demographic characteristics were summarized in Table I for the 2015 data set and Table II for the 2017 data set. The 2017 data set presented information on body mass index (BMI), smoking status, hypertension, diabetes, TNM stage and histology.

Sample collection and preparation. Blood samples $(5 \mathrm{ml})$ were collected from the forearm veins into vacuum tubes subsequent to overnight fasting. Serum was prepared by centrifugation at $3,512 \mathrm{x} \mathrm{g}$ for $10 \mathrm{~min}$ at $25^{\circ} \mathrm{C}$, and then stored at $-80^{\circ} \mathrm{C}$ until further analysis. All serum samples were prepared within $48 \mathrm{~h}$ of blood collection.
Table I. Demographic characteristics of subjects in 2015 data set.

\begin{tabular}{lccc}
\hline Characteristic & Lung cancer patients & Controls & P-value \\
\hline Patients, n & 40 & 100 & \\
Age, years & & & $0.216^{\mathrm{a}}$ \\
Mean & 66.7 & 64.1 & \\
Median & 66 & 62 & \\
Minimum & 49 & 41 & \\
Maximum & 83 & 90 & \\
Sex, n (\%) & & & $>0.999^{\mathrm{b}}$ \\
Male & $26(65)$ & $65(65)$ & \\
Female & $14(35)$ & $35(35)$ & \\
\hline
\end{tabular}

P-values were derived from ${ }^{\mathrm{a}}$ Mann-Whitney U-tests and ${ }^{\mathrm{b}} \chi^{2}$ tests.

LC-MS/MS measurement. A total of 13 types of amino acids and 8 types of acylcarnitines were measured using the LC-MS/MS method as described previously (17). Glutamine and asparagine were unstable in the serum, and were transformed into glutamate and aspartate on a large scale when stored at $4^{\circ} \mathrm{C}$ for $4 \mathrm{~h}$. In the present study, glutamine, glutamate, aspartate and asparagine were measured simultaneously using a fast LC-MS/MS method. The serum samples were deproteinized using methanol at a final concentration of $20 \%$ prior to measurement. The total concentrations of glutamate + glutamine or aspartate + asparagine were calculated as one variable. Detailed parameters of this method are presented in Table III. In order to reduce any potential bias introduced prior to analysis, all serum samples were analyzed within 3 months. The stability of fresh serum that was preserved at $4^{\circ} \mathrm{C}$ for $2,4,7,24,48$ and $72 \mathrm{~h}$, and at $-80^{\circ} \mathrm{C}$ for 10, 20,30, 60 and 90 days were investigated.

Statistical analysis. Statistical analyses were performed using SPSS software (version 17.0; SPSS, Inc., Chicago, IL, USA) and SIMCA-P 11 software (Sartorius Stedim Data Analytics $\mathrm{AB}$, Umeå, Sweden). Demographic and clinical characteristics of subjects in the two data sets were analyzed. Age and BMI between lung cancer patients and healthy controls in the two data sets were analyzed by Mann-Whitney U-tests. Sex, smoking status, hypertension and diabetes between lung cancer patients and healthy controls in the two data sets were analyzed using $\chi^{2}$ tests. The mean \pm standard deviations of amino acid and acylcarnitine concentrations were calculated for patients with lung cancer and healthy controls in the two data sets. Metabolomic data from the two data sets were analyzed using univariate [Mann-Whitney U test, Student's t-test, Welch's F test and receiver operating characteristics (ROC) curve analysis] and multivariate logistic regression analyses to screen for biomarkers in lung cancer. The metabolites, which were significantly $(\mathrm{P}<0.05)$ different in patients with lung cancer compared with healthy controls in the two data sets, were screened to be potential biomarkers. In the univariate analyses, the Shapiro-Wilk test of normality was used to examine the shape of the distribution of each variable. 
Table II. Demographic and clinical characteristics of subjects in 2017 data set.

\begin{tabular}{|c|c|c|c|}
\hline Characteristic & $\begin{array}{l}\text { Lung cancer } \\
\text { patients }\end{array}$ & Controls & P-value ${ }^{b}$ \\
\hline Patients, $n$ & 17 & 30 & \\
\hline Age, years & & & 0.176 \\
\hline Mean & 66.3 & 62.8 & \\
\hline Median & 65 & 62 & \\
\hline Minimum & 53 & 34 & \\
\hline Maximum & 77 & 85 & \\
\hline Sex, n $(\%)$ & & & $>0.999$ \\
\hline Male & $13(76.5)$ & $23(76.7)$ & \\
\hline Female & $4(23.5)$ & $7(23.3)$ & \\
\hline BMI & & & 0.563 \\
\hline Mean & 22.78 & 23.86 & \\
\hline Median & 23.24 & 22.99 & \\
\hline Minimum & 20.20 & 18.03 & \\
\hline Maximum & 25.06 & 35.92 & \\
\hline Smoking status, n (\%) & & & 0.787 \\
\hline Current & $4(23.53)$ & $7(23.33)$ & \\
\hline Previous & $5(29.41)$ & $6(20.00)$ & \\
\hline Never & $8(47.06)$ & $16(53.33)$ & \\
\hline Missing data & $0(0)$ & $1(0.33)$ & \\
\hline Hypertension, n (\%) & & & 0.343 \\
\hline Yes & $4(23.53)$ & $13(43.33)$ & \\
\hline No & $8(47.06)$ & $15(50.00)$ & \\
\hline Missing data & $5(29.41)$ & $2(6.67)$ & \\
\hline Diabetes, n (\%) & & & 0.866 \\
\hline Yes & $4(23.53)$ & $13(43.33)$ & \\
\hline No & $5(29.41)$ & $13(43.33)$ & \\
\hline Missing data & $8(47.06)$ & $4(13.33)$ & \\
\hline \multicolumn{4}{|l|}{ Stage $^{a}$, n $(\%)$} \\
\hline I & 0 & 0 & \\
\hline II & $1(5.88)$ & 0 & \\
\hline III & $2(11.76)$ & 0 & \\
\hline IV & $14(82.35)$ & 0 & \\
\hline \multicolumn{4}{|l|}{ Histology, n (\%) } \\
\hline Adenocarcinoma & $4(23.53)$ & 0 & \\
\hline Squamous cell carcinoma & $5(29.41)$ & 0 & \\
\hline Small cell lung cancer & $5(29.41)$ & 0 & \\
\hline Other types of NSCLC & $3(17.65)$ & 0 & \\
\hline
\end{tabular}

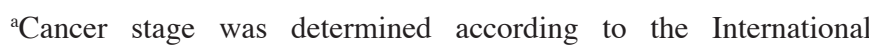
Union Against Cancer TNM Classification of Malignant Tumors, 6th Edition. ${ }^{\mathrm{b}} \mathrm{P}$-values for age and BMI were derived from the Mann-Whitney U-tests; P-values for sex, smoking status, hypertension and diabetes were derived from $\chi^{2}$ tests. BMI, body mass index; NSCLC, non-small cell lung carcinoma.

A Mann-Whitney U test was used to compare the variables without normal distribution between the patients and control groups. For variables with a normal distribution, Levene's test and the Brown-Forsythe test were used to examine the
Table III. Parameters of liquid chromatography-tandem mass spectrometry method for measuring glutamate, aspartate, glutamine and asparagine.

\begin{tabular}{|c|c|}
\hline Parameter & Value \\
\hline Mobile phase & $\begin{array}{l}\text { Water containing } 0.05 \% \\
(\mathrm{v} / \mathrm{v}) \text { formic acid }\end{array}$ \\
\hline Column & $\begin{array}{l}\text { Phenomenex Kinetex F5 } \\
\text { column }(4.6 \times 100 \mathrm{~mm}, \\
2.6 \mu \mathrm{m})\end{array}$ \\
\hline Column temperature $\left({ }^{\circ} \mathrm{C}\right)$ & 30 \\
\hline Flow rate $(\mathrm{ml} / \mathrm{min})$ & 0.3 \\
\hline Capillary voltage (kV) & 3.5 \\
\hline Drying gas temperature $\left({ }^{\circ} \mathrm{C}\right)$ & 350 \\
\hline Drying gas flow (1/min) & 10 \\
\hline Nebulizer pressure (psi) & 40 \\
\hline \multicolumn{2}{|l|}{ MRM transition (m/z) } \\
\hline Glu & $148 \rightarrow 84$ \\
\hline Gln & $147 \rightarrow 83$ \\
\hline Asp & $134 \longrightarrow 88$ \\
\hline Asn & $133 \rightarrow 87$ \\
\hline Glu-IS & $151 \rightarrow 87$ \\
\hline Asp-IS & $137 \rightarrow 91$ \\
\hline \multicolumn{2}{|l|}{ Dwell (msec) } \\
\hline Glu & 100 \\
\hline Gln & 100 \\
\hline Asp & 100 \\
\hline Asn & 100 \\
\hline Glu-IS & 100 \\
\hline Asp-IS & 100 \\
\hline \multicolumn{2}{|l|}{ Fragmentor (V) } \\
\hline Glu & 80 \\
\hline Gln & 80 \\
\hline Asp & 50 \\
\hline Asn & 50 \\
\hline Glu-IS & 80 \\
\hline Asp-IS & 50 \\
\hline \multicolumn{2}{|l|}{$\mathrm{CE}(\mathrm{eV})$} \\
\hline Glu & 18 \\
\hline Gln & 5 \\
\hline Asp & 7 \\
\hline Asn & 4 \\
\hline Glu-IS & 18 \\
\hline Asp-IS & 7 \\
\hline
\end{tabular}

Glu-IS, ${ }^{2} \mathrm{H}_{3}$-Glutamate; Asp-IS, ${ }^{2} \mathrm{H}_{3}$-Aspartate; CE, Collision Energy

equality of variances. To examine the differences between patients and controls, a Student's t-test was applied for variables with equal variances, and Welch's F test was used for variables with unequal variances. A logistic regression model was used to calculate the relevance of variables in patients with lung cancer. $\mathrm{P}<0.05$ was considered to indicate a statistically significant difference. 
A

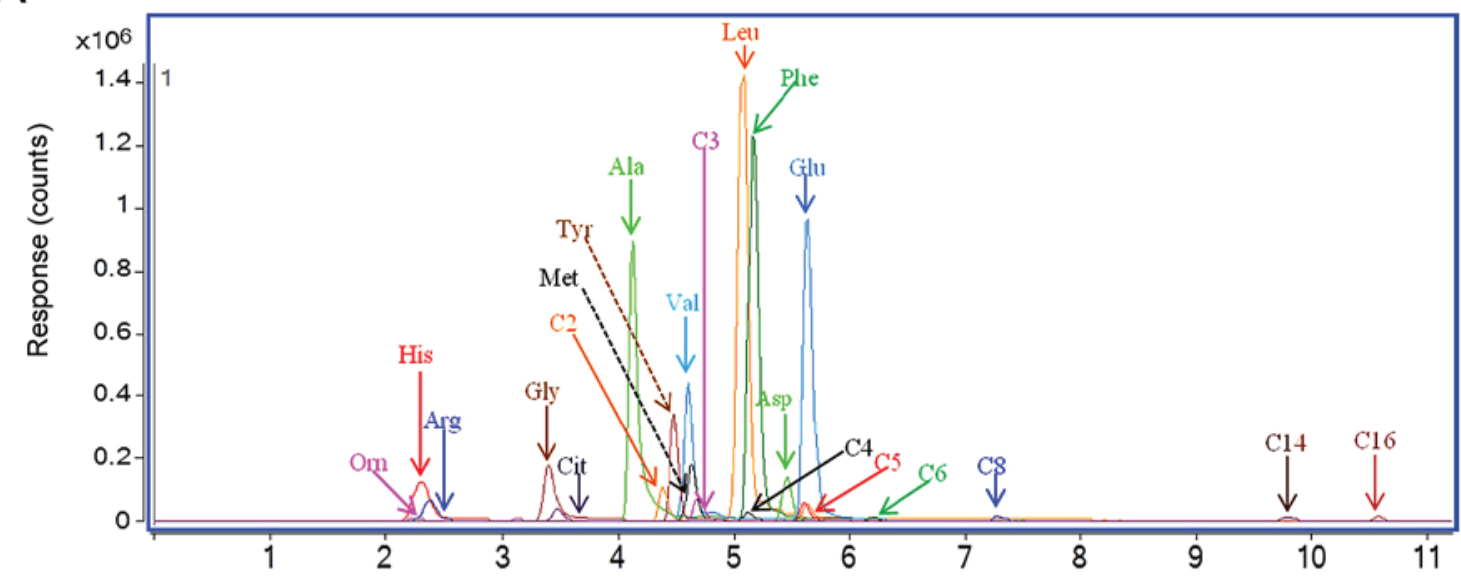

$\mathrm{B}$

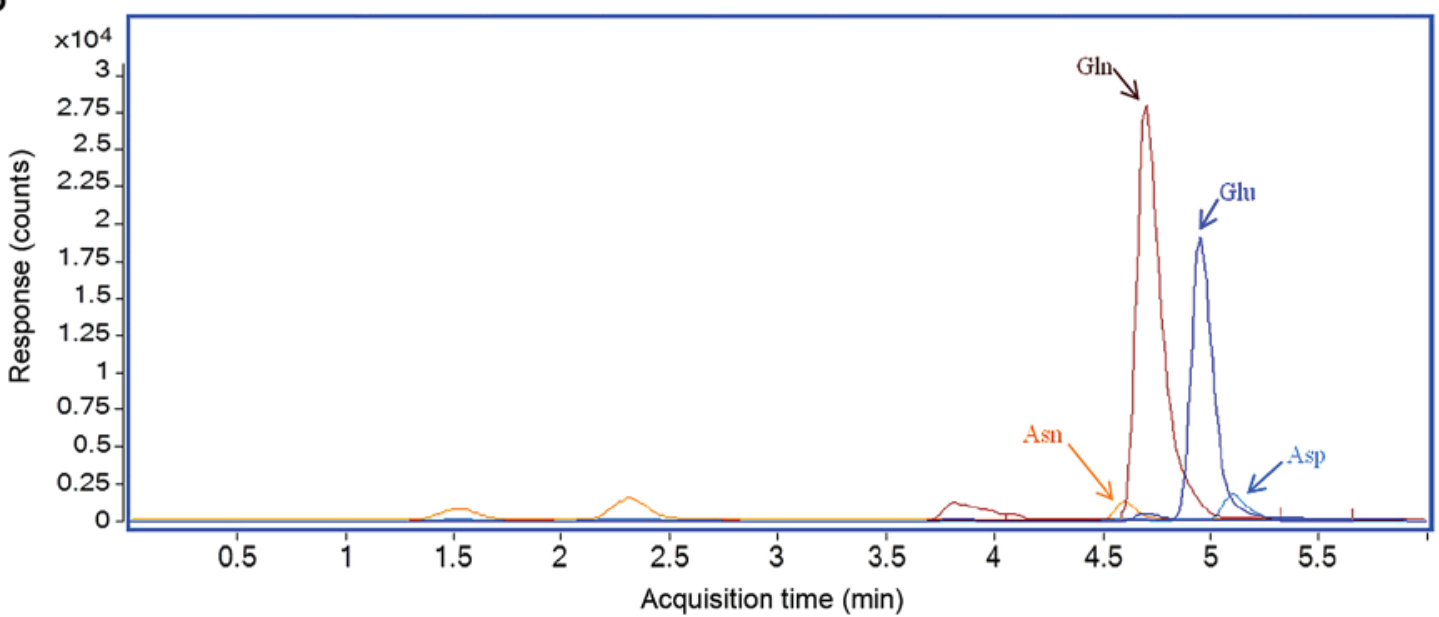

Figure 1. Representative multiple-reaction monitoring chromatography of serum samples from patients with lung cancer. (A) LC-MS/MS method measuring 21 metabolites. (B) LC-MS/MS method measuring glutamate, glutamine, aspartate and asparagine. LC-MS/MS, liquid chromatography-tandem mass spectrometry.

Partial least squares-discriminant analysis (PLS-DA). PLS-DA was performed using the screened potential biomarkers based on the 2017 data set to determine if patients with lung cancer and healthy controls could be separated. The 2017 data set was selected for PLS-DA analysis as there were no significant differences identified in the confounding factors (including age, sex, BMI, smoking status, hypertension and diabetes) between the patients with lung cancer and the healthy controls. PLS-DA was performed on log10-transformed normalized concentrations that accounted for the non-normal distribution of the concentration data and reduced the chance of skewed variables. In order to avoid over-optimization, 10-fold cross validation was performed to generate an unbiased analysis. Two parameters, R2 ('goodness-of-fit') and Q2 ('goodness-of-prediction') were calculated in the PLS-DA models.

Verification for PLS-DA Spearman's correlation analysis and ROC curve analysis were performed to verify the robustness of the established PLS-DA model. Spearman's correlation analysis was used to investigate the correlation of the first principal component from the PLS-DA model with lung cancer. ROC curve analysis was used to assess the ability of discrimination of the first principal component.

Physiological function analysis. The discriminated metabolites were queried in two databases. The human metabolomics pathway was queried using the Kyoto Encyclopedia of Genes and Genomes database (https://www.genome.jp/kegg/) and the Small Molecule Pathway Database (http://smpdb.ca/).

\section{Results}

LC-MS/MS analyses of serum samples. Multiple-reaction monitoring chromatography results of serum samples from two representative patients with lung cancer are presented in Fig. 1. The results revealed a substantial chromatographic separation of the metabolites. The serum concentrations for metabolites in the 2015 and 2017 data sets are presented in Tables IV and V, respectively. The total concentrations of glutamate+glutamine or aspartate+asparagine were calculated as one variable.

Univariate analyses. The results of the univariate analyses were presented in Table IV (2015 data set) and Table V (2017 data set). As presented in Tables IV and V, three metabolites (valine, methionine and citrulline) were decreased in the patients with lung cancer compared with the healthy controls in the two data sets. However, one metabolite (arginine) was increased in the patients with lung cancer compared with the healthy controls in the two data sets. The four metabolites (valine, methionine, citrulline and arginine) were altered 


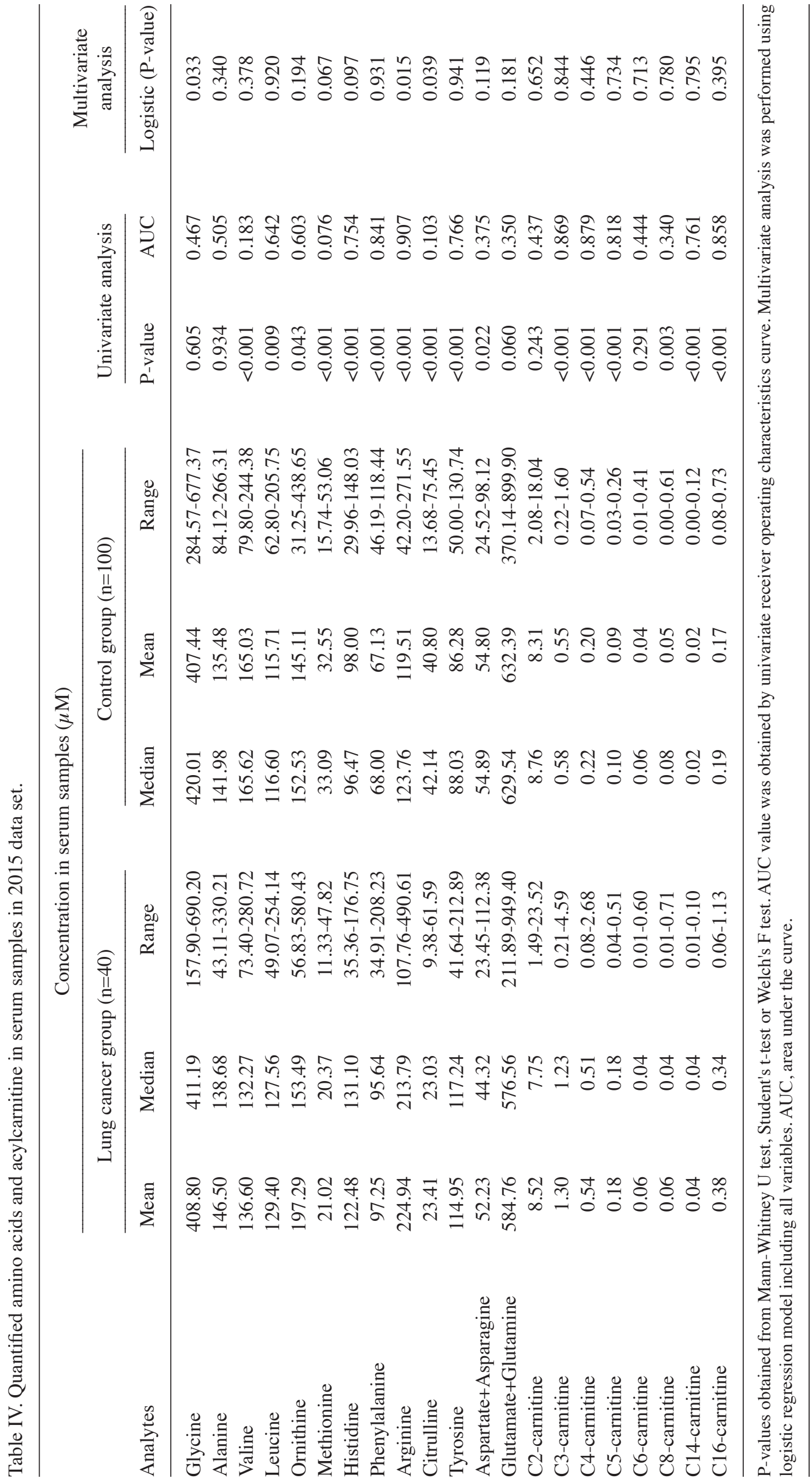




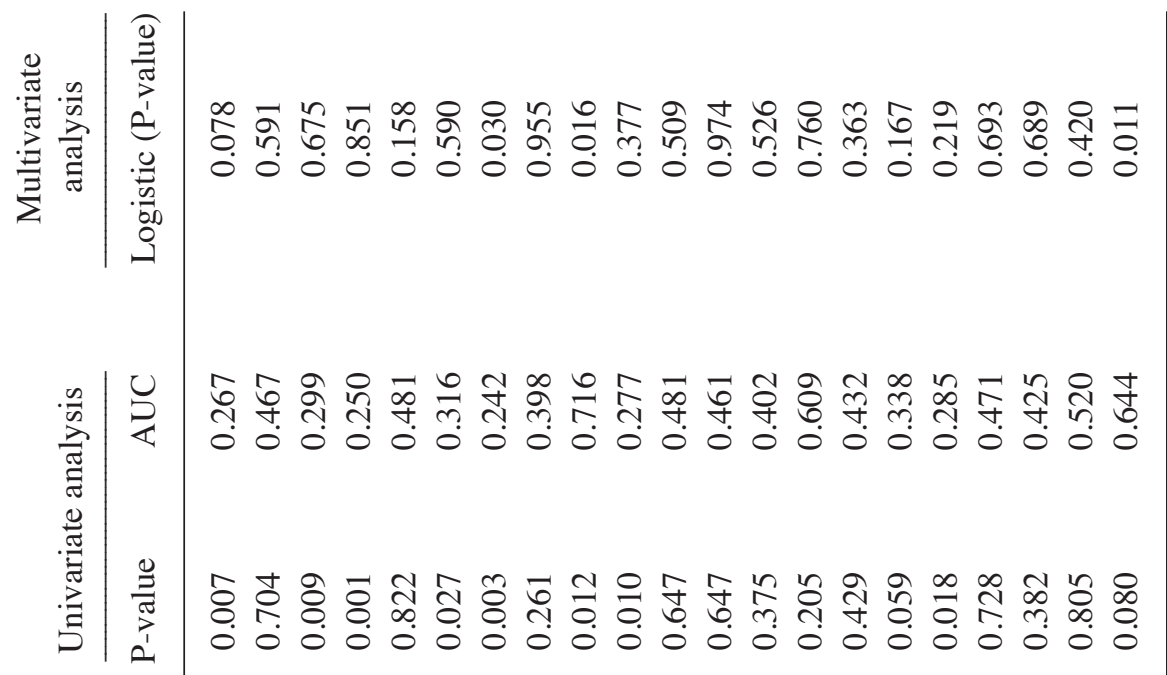

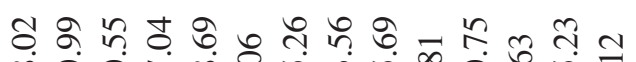

क⿺辶一兀

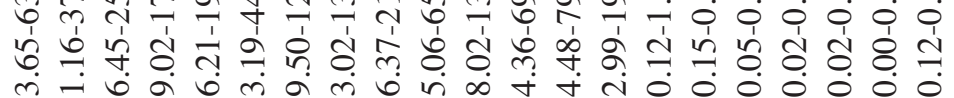
ते

유

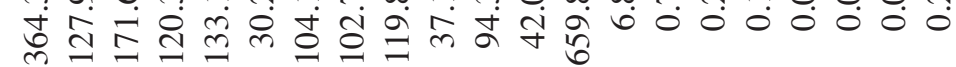

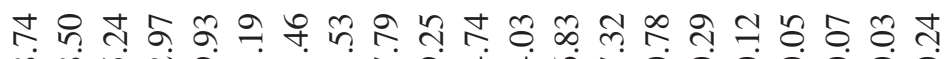
正少

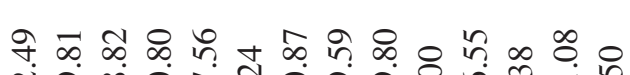

तิ श्र

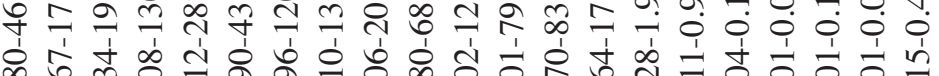

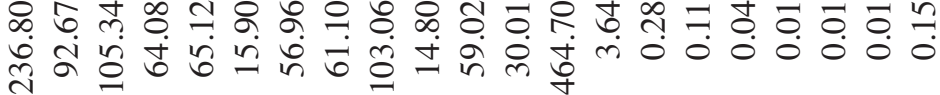
.

亏్亏

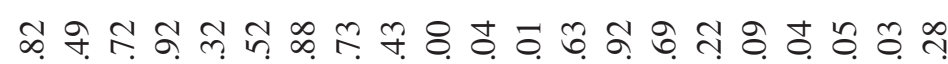
市 ป $\stackrel{00}{\Xi}$ $\Xi$

$\infty$ กิ 崩 


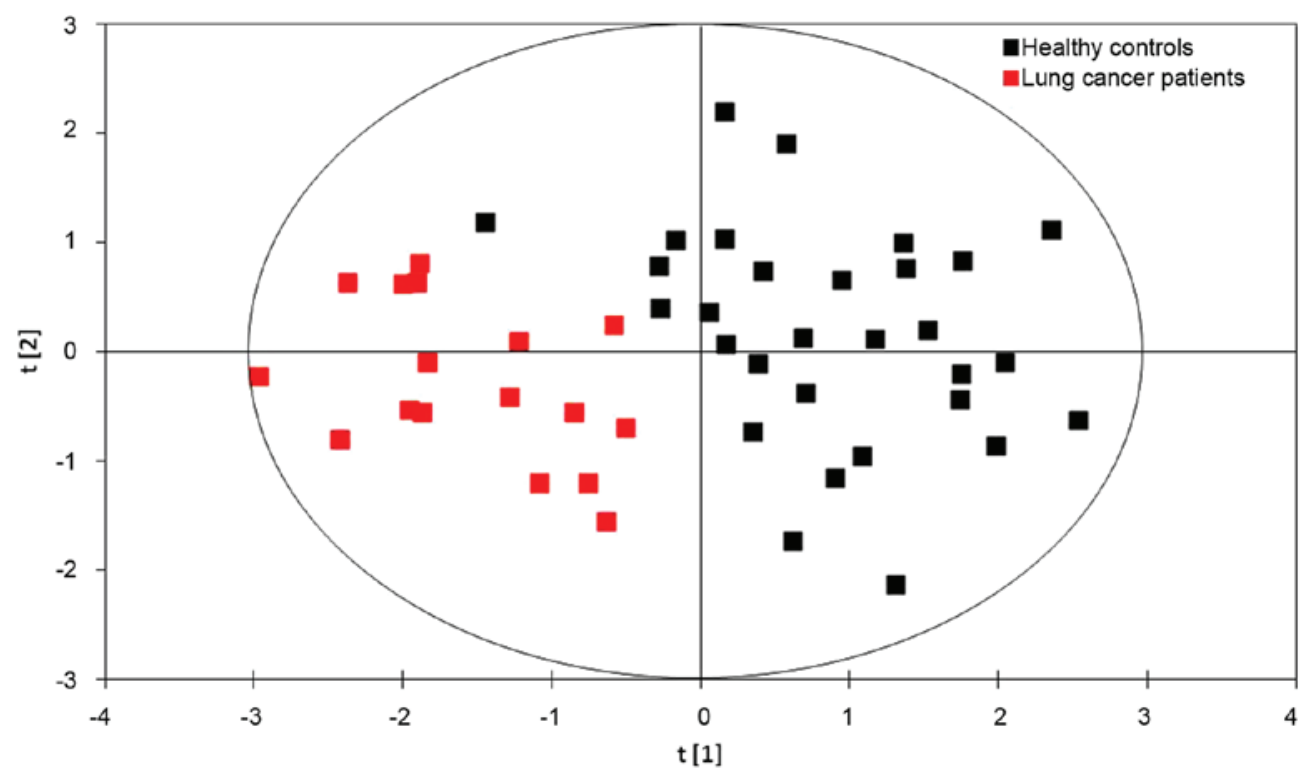

Figure 2. Score plot of partial least squares-discriminant analysis models derived from a 2017 data set. Sample points for patients with lung cancer and healthy controls were clearly separated from one another.

significantly in the patients with lung cancer in the two data sets, and these results suggested their potential to distinguish the metabolites in patients with lung cancer.

Compared with the controls, three metabolites (histidine, leucine and C5-carnitine) were increased in the patients with lung cancer in the 2015 data set, but decreased in the 2017 data set. In addition, the levels of 9 metabolites (ornithine, phenylalanine, tyrosine, aspartate + asparagine, C3-carnitine, C4-carnitine, C8-carnitine, C14-carnitine and C16-carnitine) were significantly altered in the patients with lung cancer only in the 2015 data set. This discrepancy may be caused by data set differences or the limitations of the statistical methods used. Multivariate analyses were further used to screen for the potential to identify metabolites in patients with lung cancer.

Multivariate analyses. The results of the logistic regression analyses are provided in Tables IV and V. Glycine was observed to be significantly decreased in the patients with lung cancer in the two data sets. The results revealed that the difference in the levels of glycine between the patients and the healthy controls was significant in the 2015 data set under multivariate statistical analyses, and significant in the 2017 data set under univariate analyses. C16-carnitine was revealed to be significantly different between the patients with lung cancer and the healthy controls for the 2017 data set under multivariate statistical analyses, and for the 2015 data set under univariate analyses.

Therefore, glycine and C16-carnitine were considered to be potential biomarkers for lung cancer. In total, six metabolites (glycine, valine, methionine, citrulline, arginine and C16-carnitine) were considered to be potential biomarkers for lung cancer.

PLS-DA models. The results of the PLS-DA model using six metabolites (glycine, valine, methionine, citrulline, arginine and C16-carnitine) identified from the 2017 data set are presented in Fig. 2. The first principal component $[\mathrm{t}(1)]$, is a distinguishing parameter for lung cancer based on the concentrations of the six metabolites. The formula of the first principal component was as follows:

$\mathrm{t}[1]=0.2523 \mathrm{x}$ concentration $(\mathrm{Gly})+0.6087 \mathrm{x}$ concentration $(\mathrm{Val})+0.6351 \mathrm{x}$ concentration $(\mathrm{Met})+0.0341 \mathrm{x}$ concentration $(\mathrm{Agr})+0.3084 \mathrm{x}$ concentration $(\mathrm{Cit})+0.3033 \mathrm{x}$ concentration (C16).

The formula represents the score of each lung cancer patient or healthy control in the PLS-DA model. In the model, the scores of the healthy controls were usually much lower compared with that of lung cancer patients. The above concentrations in the formula were referred to as the $\log 10$-transformed normalized concentrations.

A substantial ability to distinguish the patients with lung cancer from the healthy controls was observed with R2 $=71.9 \%$ and Q2 $=66.2 \%$ (Fig. 2). The results demonstrated that the PLS-DA model was effective for identifying patients with lung cancer. Therefore, serum concentrations of glycine, valine, methionine, citrulline, arginine and C16-carnitine may be integrated into the current method for screening for lung cancer.

Verification for PLS-DA. Results of the Spearman's correlation analysis used to assess the correlation between the first principal component from the PLS-DA model and lung cancer are presented in Fig. 3. Spearman's correlation analysis revealed that the first principal component from the PLS-DA model was significantly correlated with lung cancer. Fig. 4 revealed ROC curves for the first principal component from the PLS-DA model and 6 discriminate metabolites (glycine, valine, methionine, citrulline, arginine and C16-carnitine). The ROC curve using first principal component resulted in a high area under the curve (AUC) of 0.997, which was substantially higher compared with those using a single metabolite (citrulline, $\mathrm{AUC}=0.849$; valine, $\mathrm{AUC}=0.810$; arginine, $\mathrm{AUC}=0.747$; methionine, $\mathrm{AUC}=0.745$; glycine, 


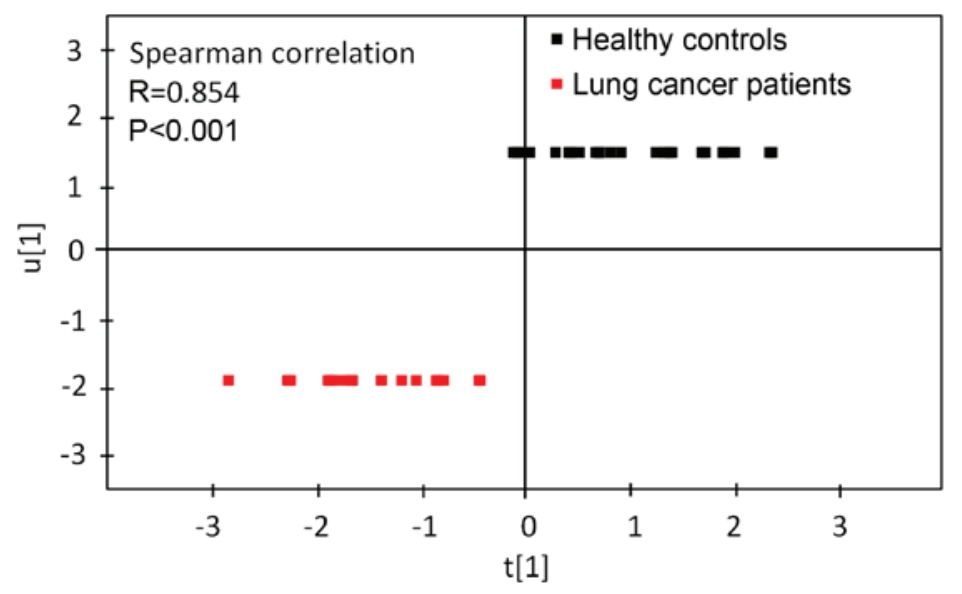

Figure 3. Spearman's correlation analysis was used to determine the correlation between the first principle component from the partial least squares-discriminant analysis and lung cancer (2017) data set.

A

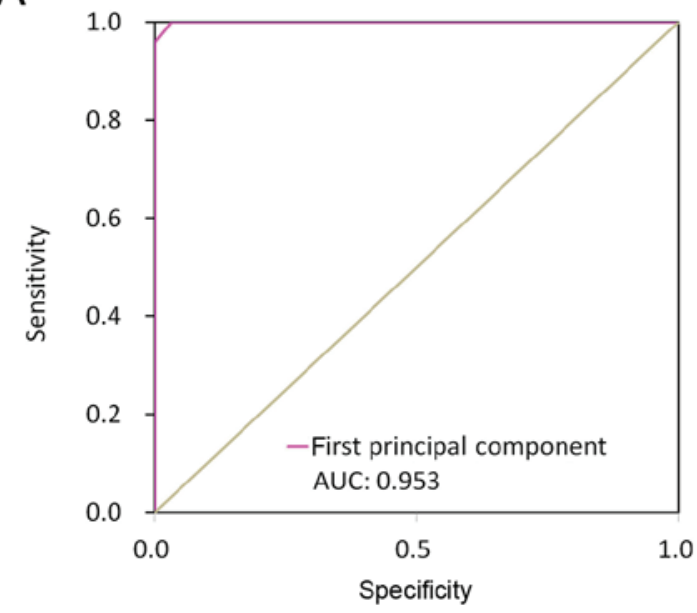

B

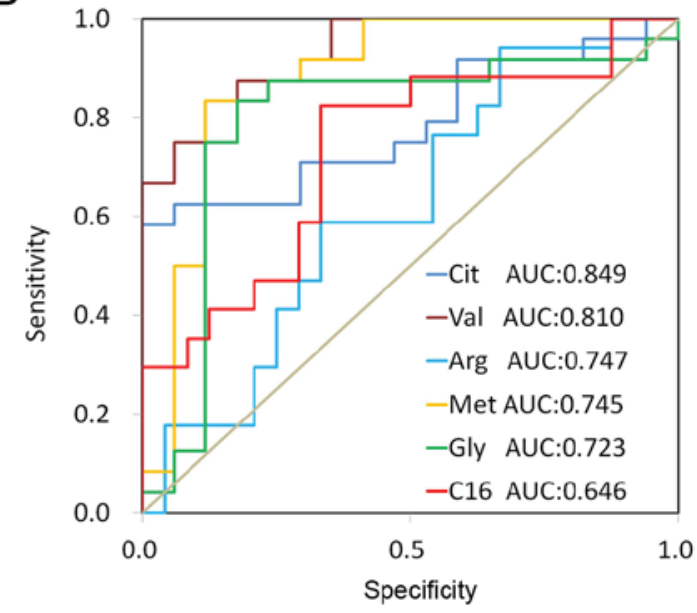

Figure 4. AUC of the first principle component and discriminant metabolites (2017 data set). (A) AUC of the first principle component: 0.953. (B) AUCs of the discriminant metabolites (citrulline, 0.849; valine, 0.810; arginine, 0.747; methionine, 0.745; glycine, 0.723; C16-carnitine, 0.646). AUC, area under the curve.

$\mathrm{AUC}=0.723$; and $\mathrm{C} 16$-carnitine, $\mathrm{AUC}=0.646$ ). These results indicated that the first principal component from the PLS-DA model demonstrated a strong ability to distinguish lung cancer.

Physiological function analysis. Physiological functions of arginine (18-32), glycine (33-41), methionine (42-48), valine (49-51), citrulline $(21,22)$ and C16-carnitine (52-54) were summarized in Table VI. The discriminating metabolites described in the table were essential for homeostasis, and the physiological disorders that occurred due to the aforementioned metabolites, including the over-biosynthesis of protein, DNA damage, hypermethylation of DNA and fatty acids $\beta$-oxidation were consistent with the tumor status. These results suggested that the discriminating metabolites may be functional substances and contribute to cancer initiation or progression.

\section{Discussion}

To the best of our knowledge, the present study is the first to build models for lung cancer screening using amino acids and acylcarnitines. The PLS-DA models using glycine, valine, methionine, citrulline, arginine and C16-carnitine exhibited a positive ability to identify lung cancer, and may function as a novel screening tool for lung cancer.

The serum concentrations of acylcarnitines from patients with lung cancer were determined using a relative quantitative method according to the peak areas, while any matrix effects may have caused deviation. In the present study, a standard curve with an isotope internal standard was performed to minimize the matrix effect. The stability study demonstrated a strong instability for glutamic acid and aspartic acid. The concentrations of glutamic acid and aspartic acid were increased subsequent to being stored at $4^{\circ} \mathrm{C}$ for $4 \mathrm{~h}$ due to the hydrolysis of glutamine and asparagine under the catalysis of metabolic enzymes (15). As the concentrations of glutamic acid, glutamine, aspartic acid and asparagine were not significantly altered subsequent to being stored at $4^{\circ} \mathrm{C}$ for $72 \mathrm{~h}$ or $-80^{\circ} \mathrm{C}$ for 3 months, the total concentration of glutamic acid + glutamine or aspartic acid + asparagine was calculated as one variable. To reduce the analytical bias caused by sample instability, the sample preparation and preservation were performed under strictly controlled conditions. All serum 
Table VI. Physiological Functions of discriminate metabolites.

\begin{tabular}{|c|c|c|c|}
\hline \multirow{2}{*}{$\begin{array}{l}\text { Discriminate } \\
\text { metabolites }\end{array}$} & \multicolumn{2}{|r|}{ Physiological functions } & \multirow[b]{2}{*}{ Physiological state in tumor } \\
\hline & Targets & Function & \\
\hline \multirow[t]{3}{*}{ Arginine } & Small molecule & $\begin{array}{l}\text { Amino acid metabolism }(18-20) \text {, } \\
\text { Trehalose degradation, urea cycle }(21,22)\end{array}$ & \\
\hline & Protein & Protein biosynthesis (23-26) & Over biosynthesis of protein $(27,28)$ \\
\hline & DNA & DNA damage through nitric oxide (NO) (29-30) & DNA damage $(31,32)$ \\
\hline \multirow[t]{3}{*}{ Glycine } & Small molecule & Amino acid metabolism $(33,34)$ & \\
\hline & Protein & Protein biosynthesis $(35,36)$ & Over biosynthesis of protein (37) \\
\hline & DNA & Antioxidant damage for DNA through uric acid & DNA damage $(38,39)$ \\
\hline \multirow[t]{3}{*}{ Methionine } & Small molecule & $\begin{array}{l}\text { Amino acid metabolism ( } 33) \text {, folate } \\
\text { metabolism ( } 40,41) \text {, betaine metabolism, } \\
\text { spermidine and spermine biosynthesis, } \\
\text { phosphatidylcholine biosynthesis ( } 42-44)\end{array}$ & \\
\hline & Protein & $\begin{array}{l}\text { Protein biosynthesis }(35,36) \text {, histone } \\
\text { methylation }\end{array}$ & $\begin{array}{l}\text { Over biosynthesis of protein, Histone } \\
\text { abnormal methylation (45-47) }\end{array}$ \\
\hline & DNA & DNA methylation & DNA abnormal methylation (45-48) \\
\hline \multirow[t]{2}{*}{ Valine } & Small molecule & $\begin{array}{l}\text { Amino acid metabolism (49), propanoate } \\
\text { metabolism }\end{array}$ & \\
\hline & Protein & Protein biosynthesis $(35,36)$ & Over biosynthesis of protein $(50,51)$ \\
\hline \multirow[t]{2}{*}{ Citrulline } & Small molecule & Amino acid metabolism, urea cycle $(21,22)$ & \\
\hline & Protein & Cyclic citrullinated peptide synthesis & \\
\hline C16-carnitine & Small molecule & Fatty acids $\beta$-oxidation (52) & Increased oxidation $(53,54)$ \\
\hline
\end{tabular}

samples were prepared within $48 \mathrm{~h}$ of blood collection, and analyzed within 3 months.

Four metabolites (glycine, valine, methionine and citrulline) were demonstrated to be significantly decreased in the serum of patients with lung cancer compared with the healthy controls in the present study. Glycine, valine and methionine are considered to be important amino acids for protein biosynthesis $(35,36)$, and are required in the development of primary tumor types $(37,50,51)$. Decreased serum levels of these metabolites may be associated with the increased uptake of circulating glycine, valine, methionine and citrulline for the rapid biosynthesis of proteins $(37,50,51)$. Glycine is a precursor for the formation of purine (55). Uric acid, a potent antioxidant in plasma (55), is a breakdown product of purine nucleotides. Therefore, the levels of uric acid present in serum are associated with the levels of glycine present. The decreased levels of glycine and uric acid may result in oxidative stress, which in turn induce oxidative damage for DNA (56) and initiate carcinogenesis. On the other hand, glycine is a crucial substrate of the deoxycholic acid glycine conjugate, which is a secondary bile acid functioning as a detergent to solubilize fats for absorption (15). The decreased levels of glycine may represent a digestive system disorder, which is a common symptom observed among patients with cancer (15).

Abnormal DNA methylation is a hallmark of lung cancer cells (57). Methionine may affect DNA methylation by regulating the levels of S-adenosyl-L-methionine, a methyl group donor, in addition to S-adenosyl-L-homocysteine, an inhibitor of enzymes catalyzing the DNA methylation reaction (46). The abnormal DNA methylation reaction may be associated with the decreased level of methionine. Citrulline is a key substance for citrullinated proteins, which may cause rheumatoid arthritis (58). Although the association between citrulline and cancer has yet to be well established, it may be inferred that rheumatoid arthritis is associated with cancer pathogenesis. Increased levels of arginine and C16-carnitine were observed in the serum of patients with lung cancer compared with the controls in the present study. Arginine is involved in the metabolism of nitric oxide (NO), a type of vasodilator and free radical that participates in the inflammatory process and carcinogenesis through nitro-oxidative stress, apoptosis, cell cycle, angiogenesis, invasion and metastasis (59). Increased arginine levels have been assumed to be the cause of increased NO (31). Therefore, arginine deprivation may offer a potential treatment method for lung cancer. Wheatley (28) demonstrated that cancer may be controlled by restricting arginine availability through inhibiting arginine-catabolizing enzymes, which function as anticancer agents. C16-carnitine may regulate $\beta$-oxidation, which was abnormally increased in non-small cell lung cancer (53). The increased $\beta$-oxidation may be associated with the high levels of C16-carnitine. Therefore, reducing C16-carnitine concentration may be a novel approach to cancer therapy (54). Limitations of the present study include a small sample size. Notable results were produced despite using a small sample size. However, replication is required in larger studies to confirm the present results. The other limitations were a lack of detailed demographic characteristics for the 2015 data set, and that the majority of patients in the 2017 cohort had advanced cancer. In further studies, lung cancer patients at early stages will be recruited to validate the model. 
The present study is, to the best of our knowledge, the first to target the approach of metabolomics for serum amino acids and acylcarnitines in patients with lung cancer. The present research provides supporting evidence that six metabolites (glycine, valine, methionine, citrulline, arginine and C16-carnitine) may be considered to be valuable biomarkers for lung cancer. The PLS-DA model using glycine, valine, methionine, citrulline, arginine and C16-carnitine exhibited a strong ability to distinguish patients with lung cancer from healthy controls. The aforementioned six metabolites may be considered to be important functional substances involved in the pathogenesis of lung cancer. In summary, these six metabolites are effective in differentiating patients with lung cancer from healthy controls, and the PLS-DA model using glycine, valine, methionine, citrulline, arginine and C16-carnitine may become a novel screening tool for lung cancer.

\section{Acknowledgements}

Not applicable.

\section{Funding}

No funding received.

\section{Availability of data and materials}

The data sets used and/or analyzed during the present study are available from the corresponding author on reasonable request.

\section{Authors' contributions}

JN drafted the manuscript. JN and LW contributed to the conception and design of the study. JN and LX performed the experiments and analyzed the data. WL and CZ contributed to the analysis of clinical information. All authors read and approved the final manuscript.

\section{Ethics approval and consent to participate}

The Regional Committee for Medical and Health Research Ethics approved the study protocol, and all patients provided written informed consent for participation in the study. All procedures performed in the present study involving human participants were in accordance with 1964 Helsinki declaration and its later amendments, or comparable ethical standards.

\section{Patient consent for publication}

Not applicable.

\section{Competing interests}

The authors declare that they have no competing interests.

\section{References}

1. Vachani A, Sequist LV and Spira A: AJRCCM: 100-year anniversary. The shifting landscape for lung cancer: Past, present, and future. Am J Resp Crit Care 195: 1150-1160, 2017.
2. An Z, Chen Y, Zhang R, Song Y, Sun J, He J, Bai J, Dong L, Zhan $Q$ and Abliz Z: Integrated ionization approach for RRLC-MS/MS-based metabonomics: Finding potential biomarkers for lung cancer. J Proteome Res 9: 4071-4081, 2010.

3. Beger RD: A review of applications of metabolomics in cancer. Metabolites 3: 552-574, 2013.

4. Deberardinis RJ and Thompson CB: Cellular metabolism and disease: What do metabolic outliers teach us? Cell 148: 1132-1144, 2012.

5. Lin HM, Barnett MP, Roy NC, Joyce NI, Zhu S, Armstrong K, Helsby NA, Ferguson LR and Rowan DD: Metabolomic analysis identifies inflammatory and noninflammatory metabolic effects of genetic modification in a mouse model of Crohn's disease. J Proteome Res 9: 1965-1975, 2010.

6. Dutta M, Joshi M, Srivastava S, Lodh I, Chakravarty B and Chaudhury K: A metabonomics approach as a means for identification of potential biomarkers for early diagnosis of endometriosis. Mol Biosyst 8: 3281-3287, 2012.

7. Xu J, Chen Y, Zhang R, Song Y, Cao J, Bi N, Wang J, He J, Bai J, Dong L, et al: Global and targeted metabolomics of esophageal squamous cell carcinoma discovers potential diagnostic and therapeutic biomarkers. Mol Cell Proteomics 12: 1306-1318, 2013.

8. Cascino A, Muscaritoli M, Cangiano C, Conversano L, Laviano A, Ariemma S, Meguid MM and Rossi Fanelli F: Plasma amino acid imbalance in patients with lung and breast cancer. Anticancer Res 15: 507-510, 1995.

9. Kubota A, Meguid MM and Hitch DC: Amino acid profiles correlate diagnostically with organ site in three kinds of malignant tumors. Cancer 69: 2343-2348, 1992.

10. Lai HS, Lee JC, Lee PH, Wang ST and Chen WJ: Plasma free amino acid profile in cancer patients. Semin Cancer Biol 15: 267-276, 2005.

11. Maeda J,Higashiyama M,Imaizumi A,Nakayama T, Yamamoto H, Daimon T, Yamakado M, Imamura F and Kodama K: Possibility of multivariate function composed of plasma amino acid profiles as a novel screening index for non-small cell lung cancer: A case control study. BMC Cancer 10: 690, 2010.

12. Rocha CM, Carrola J, Barros AS, Gil AM, Goodfellow BJ, Carreira IM, Bernardo J, Gomes A, Sousa V, Carvalho L and Duarte IF: Metabolic signatures of lung cancer in biofluids: NMR-based metabonomics of blood plasma. J Proteome Res 10: 4314-4324, 2011.

13. Miyamoto S, Taylor SL, Barupal DK, Taguchi A, Wohlgemuth G, Wikoff WR, Yoneda KY, Gandara DR, Hanash SM, Kim K and Fiehn O: Systemic metabolomic changes in blood samples of lung cancer patients identified by gas chromatography time-of-flight mass spectrometry. Metabolites 5: 192-210, 2015.

14. Wen T, Gao L, Wen Z, Wu C, Tan CS, Toh WZ and Ong CN: Exploratory investigation of plasma metabolomics in human lung adenocarcinoma. Mol Biosyst 9: 2370-2378, 2013.

15. Miyagi Y, Higashiyama M, Gochi A, Akaike M, Ishikawa T, Miura T, Saruki N, Bando E, Kimura H, Imamura F, et al: Plasma free amino acid profiling of five types of cancer patients and its application for early detection. PLoS One 6: e24143, 2011.

16. Zhao Q, Cao Y, Wang Y, Hu C, Hu A, Ruan L, Bo Q, Liu Q, Chen W, Tao F, et al: Plasma and tissue free amino acid profiles and their concentration correlation in patients with lung cancer. Asia Pac J Clin Nutr 23: 429-436, 2014.

17. Ni J, Xu L, Li W and Wu L: Simultaneous determination of thirteen kinds of amino acid and eight kinds of acylcarnitine in human serum by LC-MS/MS and its application to measure the serum concentration of lung cancer patients. Biomed Chromatog 30: 1796-1806, 2016.

18. Haake P and Allen GW: Studies on phosphorylation by phosphoroguanidinates. The mechanism of action of creatine: ATP transphosphorylase (creatine kinase). Proc Natl Acad Sci USA 68: 2691-2693, 1971.

19. Kurihara S, Oda S, Kumagai H and Suzuki H: Gamma-glutamylgamma-aminobutyrate hydrolase in the putrescine utilization pathway of Escherichia coli K-12. FEMS Microbiol Lett 256: 318-323, 2006.

20. Kurihara S, Oda S, Kato K, Kim HG, Koyanagi T, Kumagai H and Suzuki H: A novel putrescine utilization pathway involves gamma-glutamylated intermediates of Escherichia coli K-12. J Biol Chem 280: 4602-4608, 2005.

21. Lehninger AL: SMPDB: Lehninger principles of biochemistry (4th edition.). New York, WH Freeman, 2005.

22. Salway JG: Metabolism at a glance. 3rd edition. Blackwell Pub, Alden, MA, 2004. 
23. Dalbey RE and Robinson C: Protein translocation into and across the bacterial plasma membrane and the plant thylakoid membrane. Trends Biochem Sci 24: 17-22, 1999.

24. Berks BC, Sargent F and Palmer T: The Tat protein export pathway. Mol Microbiol 35: 260-274, 2000.

25. Wexler M, Sargent F, Jack RL, Stanley NR, Bogsch EG, Robinson C, Berks BC and Palmer T: TatD is a cytoplasmic protein with DNase activity. No requirement for TatD family proteins in sec-independent protein export. J Biol Chem 275: $16717-16722,2000$.

26. Jongbloed JD, Martin U, Antelmann H, Hecker M, Tjalsma H, Venema G, Bron S, van Dijl JM and Müller J: TatC is a specificity determinant for protein secretion via the twin-arginine translocation pathway. J Biol Chem 275: 41350-41357, 2000.

27. Marini JC and Didelija IC: Arginine depletion by arginine deiminase does not affect whole protein metabolism or muscle fractional protein synthesis rate in mice. PLoS One 10: e0119801, 2015.

28. Wheatley DN: Controlling cancer by restricting arginine availability-arginine-catabolizing enzymes as anticancer agents. Anticancer Drugs 15: 825-833, 2004.

29. Zhang B, Bailey WM, Kopper TJ, Orr MB, Feola DJ and Gensel JC: Azithromycin drives alternative macrophage activation and improves recovery and tissue sparing in contusion spinal cord injury. J Neuroinflammation 12: 218, 2015.

30. Katusic ZS: Role of nitric oxide signal transduction pathway in regulation of vascular tone. Int Angiol 11: 14-19, 1992.

31. Grimm EA, Sikora AG and Ekmekcioglu S: Molecular pathways: Inflammation-associated nitric-oxide production as a cancer-supporting redox mechanism and a potential therapeutic target. Clin Cancer Res 19: 5557-5563, 2013.

32. Morbidelli L, Donnini S and Ziche M: Role of nitric oxide in tumor angiogenesis. Cancer Treat Res 117: 155-167, 2004.

33. Rees WD and Hay SM: The biosynthesis of threonine by mammalian cells: Expression of a complete bacterial biosynthetic pathway in an animal cell. Biochem J 309: 999-1007, 1995.

34. Jacques SL, Nieman C, Bareich D, Broadhead G, Kinach R, Honek JF and Wright GD: Characterization of yeast homoserine dehydrogenase, an antifungal target: The invariant histidine 309 is important for enzyme integrity. Biochim Biophys Acta 1544: $28-41,2001$.

35. Bröer S: Amino acid transport across mammalian intestinal and renal epithelia. Physiol Rev 88: 249-286, 2008.

36. Bröer S; Apical transporters for neutral amino acids: Physiology and pathophysiology. Physiology (Bethesda) 23: 95-103, 2008.

37. Hayden MR and Tyagi SC: Uric acid: A new look at an old risk marker for cardiovascular disease, metabolic syndrome, and type 2 diabetes mellitus: The urate redox shuttle. Nutr Metab (Lond) 1: 10, 2004.

38. Itahana Y, Han R, Barbier S, Lei Z, Rozen S and Itahana K: The uric acid transporter SLC2A9 is a direct target gene of the tumor suppressor p53 contributing to antioxidant defense. Oncogene 34: 1799-1810, 2015.

39. Dziaman T, Banaszkiewicz Z, Roszkowski K, Gackowski D, Wisniewska E, Rozalski R, Foksinski M, Siomek A, Speina E, Winczura A, et al: 8-Oxo-7,8-dihydroguanine and uric acid as efficient predictors of survival in colon cancer patients. Int J Cancer 134: 376-383, 2014.

40. Walling J: From methotrexate to pemetrexed and beyond. A review of the pharmacodynamic and clinical properties of antifolates. Invest New Drugs 24: 37-77, 2006.

41. Desmoulin SK, Hou Z, Gangjee A and Matherly LH: The human proton-coupled folate transporter: Biology and therapeutic applications to cancer. Cancer Biol Ther 13: 1355-1373, 2012.

42. Gallego-Ortega D, Ramirez de Molina A, Ramos MA, Valdes-Mora F, Barderas MG, Sarmentero-Estrada J and Lacal JC: Differential role of human choline kinase alpha and beta enzymes in lipid metabolism: Implications in cancer onset and treatment. PLoS One 4: e7819, 2009.
43. Alatorre-Cobos F, Cruz-Ramirez A, Hayden CA, Pérez-Torres CA, Chauvin AL, Ibarra-Laclette E, Alva-Cortés E, Jorgensen RA and Herrera-Estrella L: Translational regulation of Arabidopsis XIPOTL1 is modulated by phosphocholine levels via the phylogenetically conserved upstream open reading frame 30. J Exp Bot 63: 5203-5221, 2012.

44. Henneberry AL, Wistow G and McMaster CR: Cloning, genomic organization, and characterization of a human cholinephosphotransferase. J Biol Chem 275: 29808-29815, 2000.

45. Cellarier E, Durando X, Vasson MP, Farges MC, Demiden A, Maurizis JC, Madelmont JC and Chollet P: Methionine dependency and cancer treatment. Cancer Treat Rev 29: 489-499, 2003.

46. Stefanska B, Karlic H, Varga F, Fabianowska-Majewska K and Haslberger A: Epigenetic mechanisms in anti-cancer actions of bioactive food components-the implications in cancer prevention. Br J Pharmacol 167: 279-297, 2012.

47. Guo HY, Herrera H, Groce A and Hoffman RM: Expression of the biochemical defect of methionine depend in fresh patient tumors in primary histoculture. Cancer Res 53: 2479-2483, 1993.

48. Warnecke PM and Bestor TH: Cytosine methylation and human cancer. Curr Opin Oncol 12: 68-73, 2000.

49. Xu H, Zhang Y, Guo X, Ren S, Staempfli AA, Chiao J, Jiang W and Zhao G: Isoleucine biosynthesis in Leptospira interrogans serotype lai strain 56601 proceeds via a threonine-independent pathway. J Bacteriol 186: 5400-5409, 2004.

50. Komatsu H, Nishihira T, Chin M, Doi H, Shineha R, Mori S and Satomi S: Effects of caloric intake on anticancer therapy in rats with valine depleted amino acid imbalance. Nutr Cancer 28: 107-112, 1997.

51. Zhang N, Li K, Sun X, Shou N and Jiang X: Metabolism change of gastric cancer in L-leucine/L-valine imbalance. Chin J Curr Adv Gen Surg 4: 148-151, 2001.

52. Parekh VR, Traxler RW and Sobek JM: N-Alkane oxidation enzymes of a pseudomonad. Appl Environ Microbiol 33: 881-884, 1977.

53. Harris FT, Rahman SM, Hassanein M, Qian J, Hoeksema MD, Chen H, Eisenberg R, Chaurand P, Caprioli RM, Shiota M and Massion PP: Acyl-coenzyme A-binding protein regulates beta-oxidation required for growth and survival of non-small cell lung cancer. Cancer Prev Res (Phila) 7: 748-757, 2014.

54. Ganti S, Taylor SL, Kim K, Hoppel CL, Guo L, Yang J, Evans C and Weiss RH: Urinary acylcarnitines are altered in human kidney cancer. Int J Cancer 130: 2791-2800, 2012.

55. Ohshima $\mathrm{H}$ and Bartsch $\mathrm{H}$ : Chronic infections and inflammatory processes as cancer risk factors: Possible role of nitric oxide in carcinogenesis. Mutat Res 305: 253-264, 1994.

56. Ding Y, Wang H, Niu J, Luo M, Gou Y, Miao L, Zou Z and Cheng Y: Induction of ROS overload by alantolactone prompts oxidative DNA damage and apoptosis in colorectal cancer cells Int J Mol Sci 17: 558, 2016.

57. Greenberg AK, Rimal B, Felner K, Zafar S, Hung J, Eylers E, Phalan B, Zhang M, Goldberg JD, Crawford B, et al: S-adenosylmethionine as a biomarker for the early detection of lung cancer. Chest 132: 1247-1252, 2007.

58. Sakkas LI, Bogdanos DP, Katsiari C and Platsoucas CD: Anti-citrullinated peptides as autoantigens in rheumatoid arthritis-relevance to treatment. Autoimmun Rev 13: 1114-1120, 2014.

59. Yang GY, Taboada S and Liao J: Induced nitric oxide synthase as a major player in the oncogenic transformation of inflamed tissue. Methods Mol Biol 512: 119-156, 2009.

This work is licensed under a Creative Commons Attribution-NonCommercial-NoDerivatives 4.0 International (CC BY-NC-ND 4.0) License. 